\title{
Improving the visible transmittance of low-e titanium nitride based coatings for solar thermal applications
}

\author{
M. Yuste ${ }^{a, *}$, R. Escobar Galindo ${ }^{a}$, S. Carvalho ${ }^{b}$, J.M. Albella $^{a}$, O. Sánchez $^{\text {a }}$ \\ a Instituto de Ciencia de Materiales de Madrid, Consejo Superior de Investigaciones Científicas, E-28049 Madrid, Spain

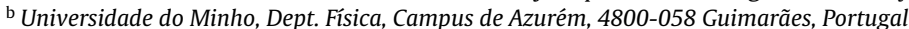

\section{A R T I C L E I N F O}

\section{Article history:}

Received 14 June 2011

Received in revised form 29 August 2011

Accepted 11 October 2011

Available online 17 October 2011

\section{Keywords:}

Low-emissivity

TiN

Magnetron sputtering

\begin{abstract}
A B S T R A C T
Low-emissivity (low-e) coatings on glass are nowadays extensively used for energy saving applications in architectural windows and on solar thermal collectors. In this work the feasibility of TiN-based layers as low-e coatings has been studied. TiN samples were deposited by reactive magnetron sputtering and, in order to improve their optical properties (transmission in the visible range, $T$ and emissivity, $\varepsilon$ ), we have investigated the changes in optical response following three different approaches: (i) post-deposition annealing treatments up to $500^{\circ} \mathrm{C}$, (ii) doping the TiN layers with aluminium (target composition: $\mathrm{Ti} / \mathrm{Al}=90 / 10,75 / 25$ and 50/50) and (iii) deposition of antireflective coatings of $\mathrm{TiO}_{2}$ in multilayers structures. The crystalline structure and chemical composition of the multilayers were studied by X-Ray Diffraction and Rutherford Backscattering Spectroscopy, respectively. Spectroscopic Ellipsometry, Fourier Transform Infrared Spectroscopy and direct emissivity measurements were employed to determine the optical properties $T$ and $\varepsilon$. We have concluded that the most noticeable improvement has been obtained by the deposition of multilayers structures increasing in a $30 \%$ the original transmittance of the single TiN coatings.
\end{abstract}

() 2011 Elsevier B.V. All rights reserved.

\section{Introduction}

The application of low-emissivity (low-e) coated glass in architectural windows and on solar thermal collectors has received much attention due to its good energy-saving performance. It is possible to block a significant amount of the radiant heat transfer to the exterior by coating the glass surface with a low-emittance material [1] and, thus, lowering the total heat flow through the glass. In the particular case of solar collectors, these heat losses entail a reduction of the efficient of the device and they can be decreased by the deposition of low-emissivity coatings on the glass cover. Low-e coatings are transparent to visible light (Transmittance, $T=80-90 \%$ ) and present high reflectance within the far infrared range reducing the emissivity coefficient, $\varepsilon$, of the glass (approximately 0.8 ). Basically two different types of coatings with low-e property are of interest for these applications: noble metal based multilayers [2-4] and large band gap semiconductor single layers [5,6]. The metal layer (usually $\mathrm{Ag}$ ) in the noble metal based multilayer coatings is very thin and these coatings are always used in sealed insulating glazing. This type of coatings presents a high

\footnotetext{
* Corresponding author. Tel.: +34 913349 000; fax: +34 913720623

E-mail address: miriam.yuste@icmm.csic.es (M. Yuste).
}

visible transmittance ( $T>80 \%)$, very low emittance values $(\varepsilon<0.2)$ and they are deposited out of the glass production line [7]. The disadvantages that this type of low-e coatings presents are related to the presence of the thin noble metal film. Firstly, they can only be used in sealed window spaces because they have shown thermal and chemical stability problems [8] and, secondly, they imply an increase of the production costs of such coatings at industrial scale. On the other hand, semiconductor single layers (usually tin or indium oxides) are transparent in the visible part of the spectrum due to their wide band gap and reflecting in the IR because of the high doping concentration. This type of low-e coatings does not achieve such a low emittance as the multilayers but their chemical stability is excellent. Furthermore, they can be deposited on the glass production line and they are cheaper than the multilayer coatings. As an alternative to these two types of low-e coatings, transition metal nitrides (TiN, ZrN and HfN) have been also proposed $[9,10]$. The primary advantage of this alternative would be the improved thermal stability, since the diffusion is much smaller for transition metal compounds than for the noble metals.

In a previous work [11] we have investigated the optical properties of TiN single thin films deposited by reactive magnetron sputtering establishing a correlation between the structure and optical properties of the coatings ( $T$ and $\varepsilon$ ). We concluded that by changing the nitrogen partial pressure, $p_{\mathrm{N}_{2}}$, and the thickness of the films, a control on the different textures can be obtained. These two parameters allow uncoupling the behaviour of the optical 


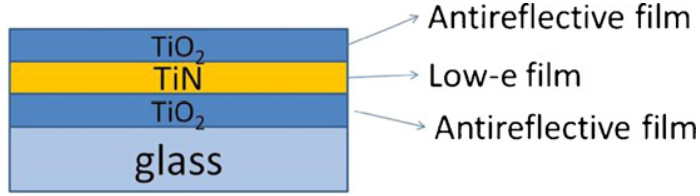

Fig. 1. Schematic representation of $\mathrm{TiO}_{2} / \mathrm{TiN} / \mathrm{TiO}_{2}$ multilayer structure: $\mathrm{TiN}$ acts as functional film (low-e) between two antireflective $\mathrm{TiO}_{2}$ layers.

properties of the films, as the visible transmittance of the coatings does not depend on the preferential orientation while the emittance clearly improves with increasing the film thickness and the presence of both (111) and (200) crystal orientations.

The purpose of the experiments reported here has been to improve the optical properties of TiN single layers. In particular we have investigated how to increase the $T$ while keeping $\varepsilon$ in a low value following three methods:

i) Post-deposition annealing treatments: it has been reported that an annealing treatment (up to $700^{\circ} \mathrm{C}$ ) after deposition improves the crystal quality of the TiN thin films by increasing the grain size [12]. This increase of the crystallinity improves the visible transmittance [13]. Furthermore, Tarniowy et al. [14] concluded that post annealing treatments on TiN films provoke a decrease of the electrical resistivity $\left(R_{\square}\right)$ of the samples. This decrease of $R_{\square}$ is related to an increase of the reflectivity in the far infrared region $\left(R_{\mathrm{IR}}\right)$ following the empirical equation $R_{\mathrm{IR}}=\left(1+0.0053 R_{\square}\right)^{-2}$ [15]. Therefore, after the annealing procedure we expect to achieve an improvement of the layer emittance as derived from Kirchhoff's law of radiation $\left(\varepsilon=1-R_{\mathrm{IR}}\right)$.

ii) Doping the TiN layers with aluminium: AlN thin films are highly transparent in the visible range [16]. Therefore, it will be expected that the incorporation of aluminium into the TiN film improves the transmittance of the original simple TiN layers by the formation of TiAlN ternary nitrides. In addition, the influence of the aluminium incorporation on the coatings emittance have been studied.

iii) Deposition of $\mathrm{TiO}_{2} / \mathrm{TiN} / \mathrm{TiO}_{2}$ multilayer structures: $\mathrm{TiO}_{2}$ is a semiconductor material transparent to visible light and it has excellent optical transmittance. Its high refractive index and good insulating properties make it a good antireflective (AR) coating $[17,18]$. It has been proved that multilayers structures improve the original transmittance of the single TiN layer $[19,20]$. Therefore, we have investigated the improvement of the TiN single layers transmittance by depositing $\mathrm{TiO}_{2} / \mathrm{TiN} / \mathrm{TiO}_{2}$ multilayer structures (see Fig. 1) together with the effect of these AR films on the TiN emittance.

\section{Experimental details}

Titanium nitride, titanium aluminium nitride coatings and $\mathrm{TiO}_{2} / \mathrm{TiN} / \mathrm{TiO}_{2}$ multilayers were deposited on single-crystal silicon $(100)$ wafers and glass substrates by dc reactive magnetron sputtering. The deposition set-up consists of a circular planar cathode, $7.5 \mathrm{~cm}$ diameter, placed in front of the substrate holder, at a distance of $13 \mathrm{~cm}$. For TiN layers a commercial titanium target of purity 99.995\% was used. A mixture of $\operatorname{Ar}(99.999 \%)$ and $\mathrm{N}_{2}$ (99.9992\%) gases was introduced in the vacuum chamber. The TiN deposition process was made at three different $p_{\mathrm{N}_{2}}$ in the reactive atmosphere, 1,30 and $40 \%$ keeping constant the total gas flow $\left(\mathrm{Ar}+\mathrm{N}_{2}\right)$ at $30 \mathrm{sccm}$. Mixed targets (purity 99.9\%) of titanium and aluminium with different $\mathrm{Ti} / \mathrm{Al}$ atomic ratios (90/10, 75/25 and 50/50) were used for the deposition of TiAlN coatings. In this case, the $\mathrm{N}_{2}$ partial pressure in the reactive atmosphere $\left(\mathrm{Ar}+\mathrm{N}_{2}=30 \mathrm{sccm}\right)$ was always set to $40 \%$. TiN layers in the multilayer structure were deposited under identical conditions that used for TiN single layers. For the deposition of the antireflective $\mathrm{TiO}_{2}$ layers, the same target of titanium was used and a mixture of $\mathrm{Ar}$ (99.999\%) and $\mathrm{O}_{2}$ (99.992\%) gases was introduced in the vacuum chamber. After a previous study of the $\mathrm{TiO}_{2}$ films deposition parameters in the sputtering system used, the $\mathrm{O}_{2}$ partial pressure was set to $4.6 \%$ with a total was flow $\left(\mathrm{Ar}+\mathrm{O}_{2}\right)$ fixed at $81 \mathrm{sccm}$. In all the deposition processes the cathode power was maintained at $100 \mathrm{~W}$, the base pressure of the chamber was typically $2 \times 10^{-4} \mathrm{~Pa}$ and the working pressure was in the range $0.46-0.63 \mathrm{~Pa}$. No intentional heating was used during the deposition process, though the process temperature of the substrates was relatively constant at $100^{\circ} \mathrm{C}$. Prior to deposition, 20 min of presputtering have been performed in order to remove the metal oxide layer of the cathode due to previous deposits. The samples were grown after the total poisoning of the titanium target to ensure we were working under the reactive sputtering regime. Other details of the sputtering system have been described previously [21].

The thickness of the films deposited on silicon and glass substrates was measured using a mechanical stylus profilometer (Veeco Dektak 150). Crystalline structure was determined by XRay Diffraction (XRD) working under grazing incidence conditions (angle of incidence $0.7^{\circ}$ ) using a $\mathrm{Cu}$ anode $(\mathrm{Cu} \mathrm{K} \alpha=1.54 \AA$ ) at room temperature. The XRD measurements were performed on a Siemens D-5000 difractometer. Grain sizes shown were obtained following the Scherrer equation. Spectroscopic Ellipsometry (SE) determined the refractive index, $n$ and extinction coefficient, $k$ in the visible range. Measurements were performed on an M-2000U ellipsometer working in the range $250-1600 \mathrm{~nm}$ and under an incidence angle of $70^{\circ}$. The visible transmittance of the single layer coatings deposited on glass substrates was calculated from $n$ and $k$ measurements following the equations for a system of an absorbing plane parallel thin film on a non-absorbing substrate [22]. The transmittance of the multilayers, grown on glass substrates, was measured with a Varian Cary 4000 spectrophotometer working in the range $200-800 \mathrm{~nm}$. Reflectance values in the medium and far infrared range $(1.5-18 \mu \mathrm{m})$ were obtained using a Bruker IFS $60 \mathrm{~V}$ Fourier transform infrared spectrometer (FTIR). These measurements were carried out using the samples grown on silicon substrates. The corresponding $\varepsilon$ values were determined from the experimental infrared reflectance values $\left(\varepsilon=1-R_{\mathrm{IR}}\right)$. The emittance calculated from infrared reflectance experiments (also known as normal emittance) has been corrected according to the European standard EN673. Direct emittance measurements of the multilayers samples have been carried out with an emissometer model AE1 from Devices \& Service Company. For the study of the quality of the interfaces and the chemical composition of the individual layers in the $\mathrm{TiO}_{2} / \mathrm{TiN} / \mathrm{TiO}_{2}$ structures, grown on silicon substrates, Rutherford Backscattering Spectroscopy (RBS) experiments were performed with the 5 MV HVEE Tandetron accelerator sited at the Centro de Micro-Análisis de Materiales of Universidad Autónoma de Madrid [23]. The RBS experiments were performed both using 3.7 $\mathrm{MeV} \mathrm{He}^{+}$ions to make use of the resonance ${ }^{14} \mathrm{~N}(\alpha, \alpha)$ ${ }^{14} \mathrm{~N}$ in order to improve the sensitivity to nitrogen, and $1.0 \mathrm{MeV} \mathrm{He}^{+}$ ions with the sample tilted $\left(\alpha=45^{\circ}\right)$ to improve the depth resolution of the RBS analysis. The experimental spectra were fitted with the software program RBX [24]. Post deposition annealing treatments were carried out in vacuum $\left(P=4 \times 10^{-3} \mathrm{~Pa}\right)$ for $30 \mathrm{~min}$ at different temperatures $\left(250,400\right.$ and $\left.500^{\circ} \mathrm{C}\right)$ in a resistive furnace. The heating rate was $4{ }^{\circ} \mathrm{C} / \mathrm{min}$ from room temperature to annealing temperature. 

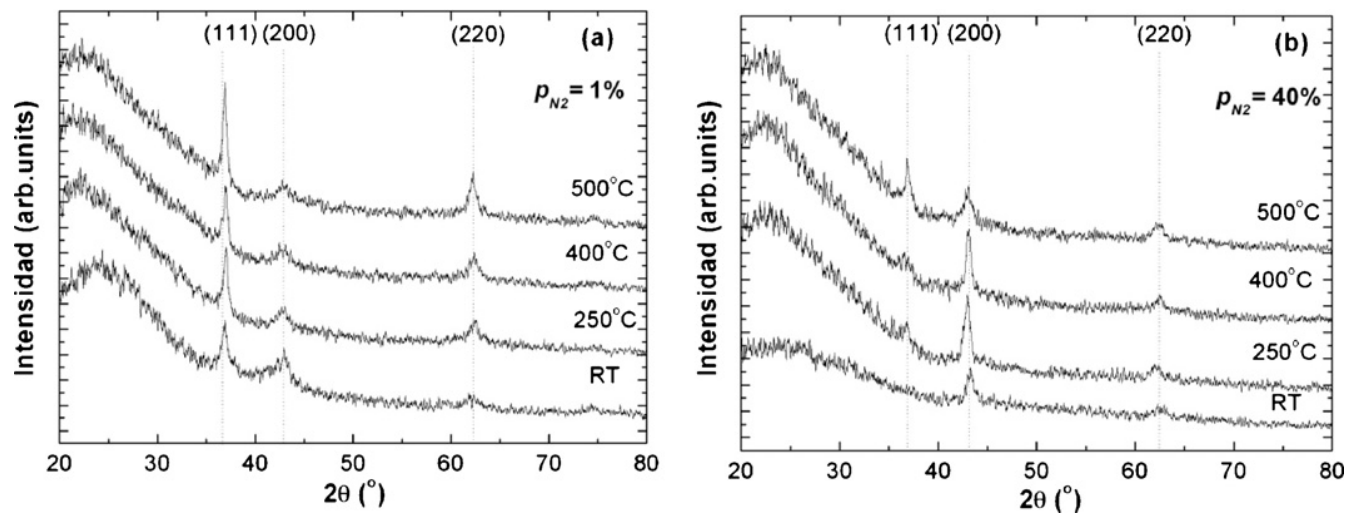

Fig. 2. XRD patterns of as deposited and annealed at 250,400 and $500{ }^{\circ} \mathrm{C}$ TiN samples with (a) nitrogen partial pressure of $1 \%$ and (b) nitrogen partial pressure of $40 \%$.

\section{Results and discussion}

\subsection{Post-deposition annealing treatment of the TiN single layers}

TiN single layers deposited with $p_{\mathrm{N}_{2}}=1,30$ and $40 \%$ (hereafter TiN-1, TiN-30 and TiN-40) have been annealed in vacuum at 250, 400 and $500{ }^{\circ} \mathrm{C}$ after deposition. In Ref. [11] we showed that the nitrogen incorporated to the as deposited samples TiN-1, TiN-30 and TiN-40 was $36 \pm 3,53 \pm 2$ and $51 \pm 4$ at.\%, respectively. The XRD patterns in Fig. 2 show the influence of post-annealing treatments in the crystalline structure of the TiN layers deposited on glass using $1 \%$ (Fig. 2a) and $40 \%$ (Fig. 2 b) of $\mathrm{N}_{2}$ partial pressure. For TiN-1 sample, no changes in the preferred (111) orientation have been observed. There is a progressive narrowing of this main peak after each heat treatment indicating an increase of the grain size (from $24 \pm 1 \mathrm{~nm}$ for the as deposited sample to $38 \pm 2 \mathrm{~nm}$ after annealing at $500^{\circ} \mathrm{C}$ ). On the other hand, the high temperature treatment has had a clear effect on the crystalline structure for TiN samples grown at 30 and $40 \%$ of $\mathrm{N}_{2}$ partial pressure. In these samples the (200) orientation remains as the preferential orientation, with an increase of the grain size, after treatments at 250 and $400{ }^{\circ} \mathrm{C}(18 \pm 1 \mathrm{~nm}$ for the TiN-40 as deposited sample and $19 \pm 1$ and $29 \pm 3 \mathrm{~nm}$ for the annealed samples at 250 and $400{ }^{\circ} \mathrm{C}$, respectively). However, once samples are annealed at $500^{\circ} \mathrm{C}$, there is a change in the crystalline structure resulting in a competition between (111) and (200) phases with no preferential orientation (see Fig. $2 \mathrm{~b}$ for TiN-40). The optical constants, $(n, k, T, \varepsilon)$ were calculated for TiN samples both as deposited and annealed at the three different temperatures in order to study the influence of the temperature in these properties. We have just observed meaningful changes in those samples where a competition in the preferred orientations occurs after annealed at $500{ }^{\circ} \mathrm{C}$ (samples $\mathrm{TiN}-30$ and $\mathrm{TiN}-40$ ). For example, as deposited TiN-40 sample has a thickness of $33 \mathrm{~nm}$ and presents a visible transmittance at $600 \mathrm{~nm}$ of $28 \%$ with an emissivity of $0.70 \pm 0.01$. After annealing the sample at $500^{\circ} \mathrm{C}$ the thickness reduces to $23 \mathrm{~nm}$, the emittance keeps at $0.69 \pm 0.01$ and the transmittance increases up to $40 \%$. In Ref. [11] we reported that the emittance of an as deposited TiN-40 sample with the same thickness of $23 \mathrm{~nm}$ was above 0.80 . Hence, this emittance is significantly higher than the obtained for the annealed sample shown in this paper. It is worth noting that this sample presented a (200) preferential orientation. Therefore, the high temperature annealing has entailed two effects. On the first hand, there is a reduction of the layer thickness producing a increase of $12 \%$ of the visible transmittance. This layer thickness reduction would result in a detrimental increase of the emittance in a non annealed sample. However, the heat treatment also provokes the appearance of both (111) and (200) orientations avoiding the increase of the emittance, in agreement with previous work [11] where it was reported that samples with both crystal orientations presented the lowest emittance values. These two effects have been observed in samples grown with high nitrogen partial pressure (30 and 40\%). Table 1 shows a summary of the TiN thicknesses and properties measured as deposited and after annealed at $500^{\circ} \mathrm{C}$.

Therefore, the post deposition annealing treatments at $500^{\circ} \mathrm{C}$ improve the transmittance of the TiN single layers while keeping the emittance. However, neither the absolute values of transmittance nor emittance obtained in these samples are suitable to be used as effective low-e coatings.

\subsection{Aluminium doping of TiN single coatings}

TiAlN films were deposited using mixed targets with different $\mathrm{Ti} / \mathrm{Al}$ atomic ratios and a constant partial pressure of nitrogen of $40 \%$ to study the influence of the aluminium on the transmittance and emittance properties. The thickness of the deposited layers was $50 \pm 5 \mathrm{~nm}$

In Fig. 3 the XRD patterns show the influence of the Ti/Al atomic ratio (in the target) in the crystalline structure of the coatings. The samples deposited with different at. ratios (90/10,75/25 and 50/50) are compared to a $50 \mathrm{~nm}$ binary TiN sample deposited under the same conditions $\left(p_{\mathrm{N}_{2}}=40 \%\right)$. For the TiN sample the registered peaks correspond to the (111), (200) and (220) planes of the TiN cubic phase (see JCPDS card $\mathrm{N}^{\circ} 38-1420$ [25]). A progressive shift of these diffraction peaks to higher $2 \theta$ angles is observed when

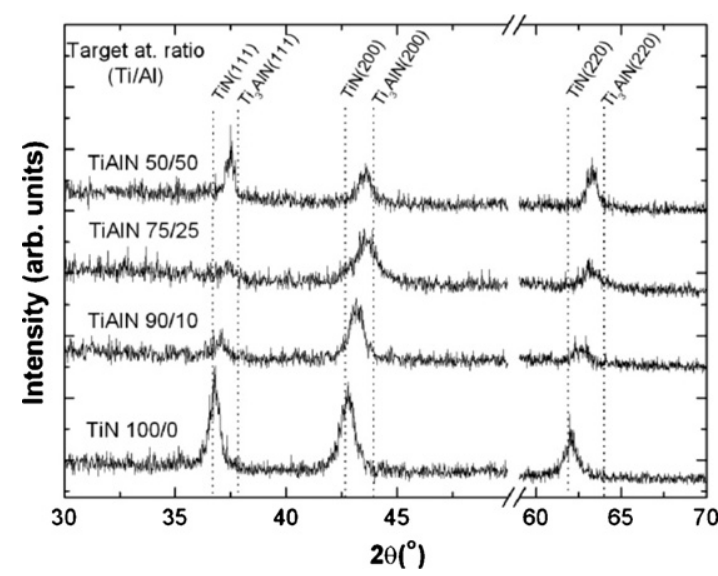

Fig. 3. XRD patterns of a TiN film deposited at $p_{\mathrm{N}_{2}}=40 \%$ and TiAlN films deposited under the same conditions and with different Ti/Al atomic ratios in the target (90/10, $75 / 25$ and 50/50). The thickness in all deposited samples was $\sim 50 \mathrm{~nm}$. 
Table 1

Summary of the TiN properties measured as deposited and after annealed at $500{ }^{\circ} \mathrm{C}$.

\begin{tabular}{|c|c|c|c|c|c|c|}
\hline Sample & $\begin{array}{l}\text { Annealing } \\
\text { temperature }\left({ }^{\circ} \mathrm{C}\right)\end{array}$ & Thickness (nm) & $\begin{array}{l}\text { Transmittance (\%), } \\
600 \mathrm{~nm}\end{array}$ & $\begin{array}{l}\text { Emittance, } 8 \mu \mathrm{m} \\
( \pm 0.01)\end{array}$ & $\begin{array}{l}\text { Preferential } \\
\text { orientation }\end{array}$ & Grain size $^{\mathrm{a}}(\mathrm{nm})$ \\
\hline \multirow{2}{*}{ TiN-1 } & As deposited & $37 \pm 3$ & $33 \pm 2$ & 0.74 & $(111)$ & $24 \pm 1$ \\
\hline & 500 & $37 \pm 3$ & $29 \pm 2$ & 0.75 & (111) & $38 \pm 2$ \\
\hline \multirow{2}{*}{ TiN-30 } & As deposited & $26 \pm 4$ & $33 \pm 2$ & 0.72 & $(200)$ & $29 \pm 2$ \\
\hline & 500 & $23 \pm 5$ & $39 \pm 2$ & 0.73 & $(111)+(200)$ & $30 \pm 3_{(111)} / 13 \pm 1_{(200)}$ \\
\hline \multirow{2}{*}{ TiN-40 } & As deposited & $33 \pm 7$ & $28 \pm 2$ & 0.70 & $(200)$ & $18 \pm 1$ \\
\hline & 500 & $23 \pm 2$ & $40 \pm 2$ & 0.69 & $(111)+(200)$ & $31 \pm 2_{(111)} / 16 \pm 2_{(200)}$ \\
\hline
\end{tabular}

a Calculated from the preferential orientation peaks.
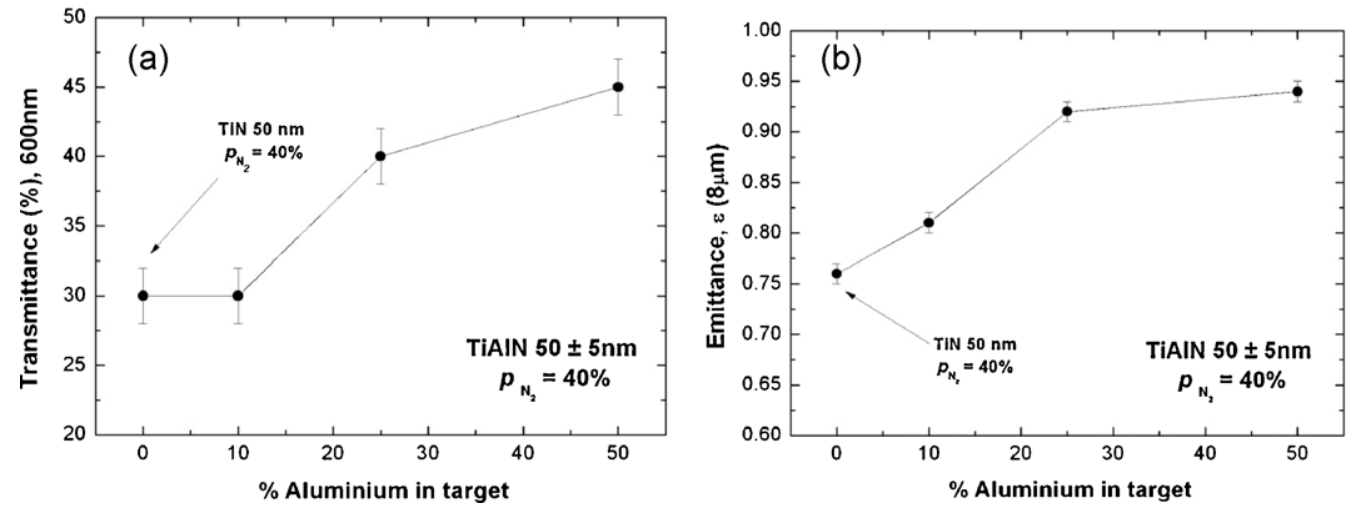

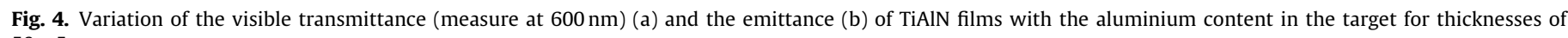
$50 \pm 5 \mathrm{~nm}$.

increasing the aluminium content in the target. This shift brings nearer the abovementioned planes to the corresponding diffraction positions of the ternary compound $\mathrm{Ti}_{3} \mathrm{AlN}$ (JCPDS card $\mathrm{N}^{\circ}$ 37-1140 [25]). Therefore, the X-ray patterns confirm that, by increasing the $\mathrm{Al}$ at. content in the target, the incorporation of the aluminium in the TiN network provokes the formation of a ternary compound. Fig. 4a shows the transmittance (at $600 \mathrm{~nm}$ ) of TiAlN films as a function of the aluminium content in the different targets. The improvement of the transmittance is obvious when compared with a TiN single layer of the same thickness and grown under the same $p_{\mathrm{N}_{2}}$. The transmittance of the TiAlN samples increases with the aluminium content, from $30 \%$ ( 0 at.\% $\mathrm{Al}$ ) to $45 \%$ when a target with at. ratio $\mathrm{Ti} / \mathrm{Al}=50 / 50$ is used. Fig. $4 \mathrm{~b}$ shows the variation of the emittance, calculated from FTIR measurements, with the aluminium content in the target. As it can be seen, a TiN sample with $50 \mathrm{~nm}$ of thickness presents an emittance of 0.79 which increases until 0.94 when the aluminium content in the target is $50 \%$.

Therefore, despite the beneficial increase of the transmittance, the aluminium doping of TiN provokes a negative effect on the emittance and these ternary layers are also not suitable to be used as proper low-e coatings.

\subsection{Deposition of $\mathrm{TiO}_{2} / \mathrm{TiN} / \mathrm{TiO}_{2}$ multilayer structures}

$\mathrm{TiO}_{2} / \mathrm{TiN} / \mathrm{TiO}_{2}$ structures were deposited with a fixed $\mathrm{TiO}_{2}$ thickness of $38 \mathrm{~nm}$ and different TiN thicknesess $(26-90 \mathrm{~nm})$ and $p_{\mathrm{N}_{2}}$ (1 and 40\%). In this structure, the TiN acts as a low emissivity film between two $\mathrm{TiO}_{2}$ layers working as antireflective films. Fig. 5 shows the $1 \mathrm{MeV} \mathrm{He}^{+} \mathrm{RBS}$ spectra (experimental data and the RBX fit results) where the multilayer structure is resolved. The peak assigned to titanium can be divided in three contributions: (1) at high energy ( $\sim 705 \mathrm{keV}$ ) appears the titanium on the surface oxide $\left(\mathrm{TiO}_{2-} 1\right)$, (2) at $\sim 655 \mathrm{keV}$, there is a high intensity peak corresponding to the intermediate TiN layer and finally (3) at lower energy $(\sim 610 \mathrm{keV})$ appears the titanium of the second $\mathrm{TiO}_{2}$ deposited on the substrate $\left(\mathrm{TiO}_{2}-2\right)$. The inset in Fig. 5 shows the chemical composition of the individual layers in the multilayer structure calculated from RBX. The titanium, nitrogen and oxygen content in the TiN layer are 52, 32 and 16 at.\%, respectively. The two $\mathrm{TiO}_{2}$ layers have the same composition: $\mathrm{Ti}=26-27$ at.\%, $\mathrm{O}=62-63$ at.\% and $\mathrm{N}=11$ at.\%. The adventitious presence of oxygen and nitrogen into the $\mathrm{TiN}$ and $\mathrm{TiO}_{2}$ layers respectively, is due to the layer intermixing entailing the formation of $\mathrm{TiO}_{x} \mathrm{~N}_{y}$ interfaces during the deposition process. To study the effect of the $\mathrm{AR} \mathrm{TiO}_{2}$ layers on the emittance of the TiN in the multilayer structure, simple (TiN) and multilayer coatings $\left(\mathrm{TiO}_{2} / \mathrm{TiN} / \mathrm{TiO}_{2}\right)$ with intermediate TiN layer grown under identical conditions (nitrogen partial pressure and time deposition) have been deposited. After the measurement of their emittance, a difference of \pm 0.02 between single TiN and multilayers has been observed. This difference, within the error of the TiN thickness during the deposition process, is not significant so we can conclude that the AR layers do not affect the TiN emittance. Regarding transmittance, in Fig. 6a and b the open circles represent the dependence

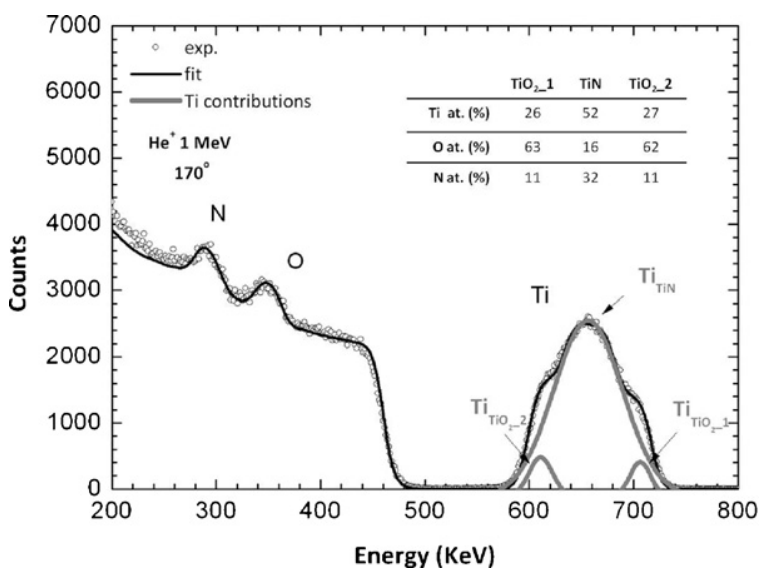

Fig. 5. RBS profile (experimental data and fit results) and chemical composition calculated from $\mathrm{RBX}$ of a $\mathrm{TiO}_{2} / \mathrm{TiN} / \mathrm{TiO}_{2}$ multilayer structure. 

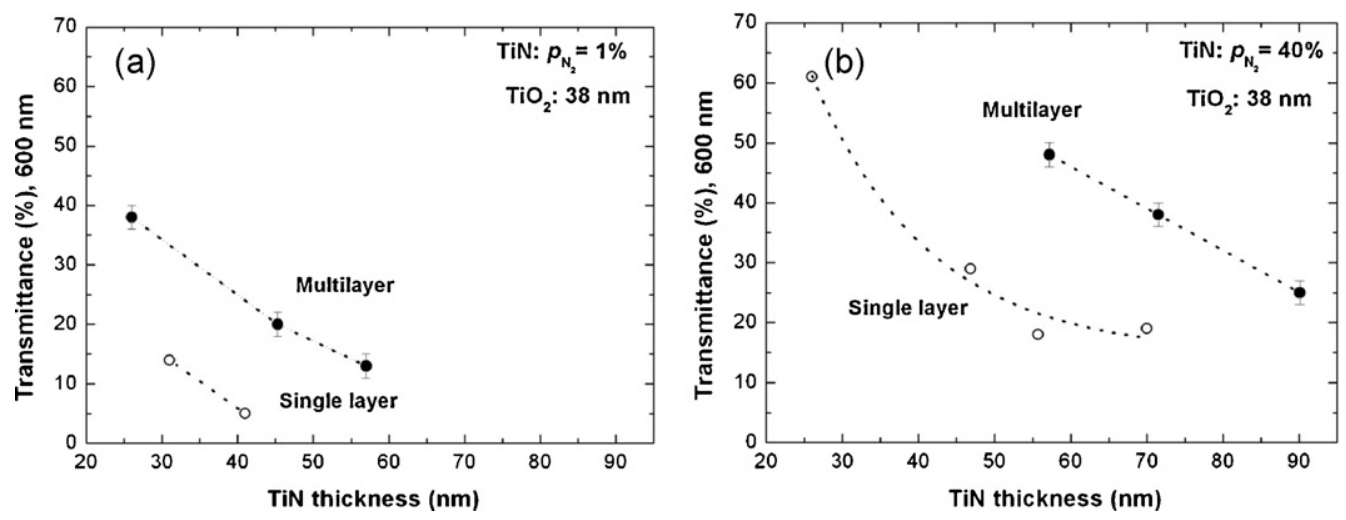

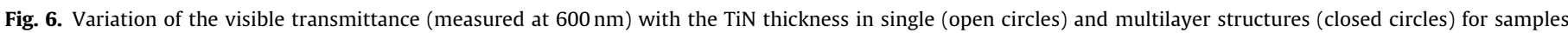
deposited with (a) $1 \%$ of nitrogen partial pressure and (b) $40 \%$ of nitrogen partial pressure.

of $T$ (at $600 \mathrm{~nm}$ ) with the thickness for TiN single layers deposited with $p_{\mathrm{N}_{2}}=1$ and $40 \%$, respectively. The closed circles represent the transmittances of multilayers where the $\mathrm{TiO}_{2}$ thickness is constant $(38 \mathrm{~nm})$ and the TiN thickness is variable. It can be observed how the transmittance of the single TiN coatings can be increased and improved by the antireflective $\mathrm{TiO}_{2}$ films. In both cases the multilayer structures present higher transmittance values than the single TiN $\left(T_{\text {multilayer }}-T_{\text {single TiN }}>15 \%\right)$ and it is possible to increase it from 18 (single TiN) to $48 \%$ (TiN in multilayer) for a TiN thickness of $56 \mathrm{~nm}$ and $p_{\mathrm{N}_{2}}=40 \%$ (see Fig. 6b) keeping the emittance at 0.58 . Similar trend is observed for other nitrogen partial pressures and thicknesses (Fig. 6a and b). Therefore, it is possible to improve the transmittance of the TiN layers by depositing multilayers structures with AR films which are easily to scale up to industrial production by the sputtering magnetron technique.

\section{Conclusions}

We have studied three strategies aiming to improve the optical properties of TiN single layers used as low-e coatings: (i) post-deposition annealing treatment of the TiN single layers, (ii) aluminium doping of TiN coatings and (iii) deposition of $\mathrm{TiO}_{2} / \mathrm{TiN} / \mathrm{TiO}_{2}$ multilayer structures. We have shown that doping the TiN layers with aluminium improves the transmittance of the TiN films but at the expenses of a detrimental increase of their $\varepsilon$. On the other hand it has been also demonstrated that post deposition annealing treatments improve in a $10 \%$ the transmittance at room temperature while keeping constant the emittance. Finally, multilayers structures present the best results by improving in a $30 \%$ the transmittance of the TiN single layers without degrading the emittance. The use of multilayer structures is the best strategy in order to promote the TiN possibilities and bring its optical properties closer to the required values. But, despite the improvement achieved by using AR coatings, the obtained values are clearly far to the optimum transmittance and emittance necessary for low-e applications. Therefore, it is still necessary to optimize the multilayer system by the improvement of the interfaces and the optimization of the TiN and antireflective $\mathrm{TiO}_{2}$ thicknesses.

\section{Acknowledgments}

This work was financially supported by the Spanish Ministry of Science and Innovation (projects FUNCOAT CSD2008-00023 and MAT2008-06618-C02-02). REG wish also to thank the MCINN for the financial support within the Ramón y Cajal programme.

\section{References}

[1] J.A. Duffie, W.A. Beckman, Solar Engineering of Thermal Processes, Jonh Wiley \& Sons, New Jersey, 2006.

[2] R.J. Martín-Palma, L. Vázquez, J.M. Martínez-Duart, Malats-Riera, Sol. Energy Mater. Sol. Cells 53 (1998) 55.

[3] K. Kato, H. Omoto, A. Takamatsu, Vacuum 83 (3) (2008) 606.

[4] G. Leftherioti, P. Yianoulis, Sol. Energ. Mat. Sol. Cells 58 (1999) 185

[5] M. Okada, Y. Yamada, P. Jin, M. Tazawa, K. Yoshimura, Thin Solid Films 442 (2003) 217.

[6] G. Mavrodiev, M. Gajdardziska, N. Novkovski, Thin Solid Films 113 (1984) 93.

[7] M. List, C. Melde, J. Krause, C. Köckert, Vak. Forsch. Prax. 16 (2004) 222

[8] B. Karlsson, E. Valkonen, T. Karlsson, C.G. Ribbing, Thin Solid Films 86 (1981) 91.

[9] B.C. Karlsson, -G. Ribbing, Proc. Soc. Photo-Opt. Instrum. Eng. 324 (1982) 52.

[10] P. Zheng, G. Zhao, T. Zhang, L. Wu, J. Wang, G. Han, Chin. Sci. Bull. 52 (13) (2007) 1860.

[11] M. Yuste, R. Escobar Galindo, O. Sánchez, D. Cano, R. Casasola, J.M. Albella, Thin Solid Films 518 (2010) 5720.

[12] M.A. Auger, O. Sánchez, J.M. Albella, Bol. Soc. Esp. Ceram. Vidrio 45 (2006) 75.

[13] W-L. Hsu, Y-H. Pai, F-S. Meng, C-W. Liu, G-R. Lin, Appl. Phys. Lett. 94 (2009) 231906.

[14] A. Tarniowy, R. Mania, M. Rekas, Thin Solid Films 311 (1997) 93.

[15] G. Frank, E. Kauer, H. Köstlin, Thin Solid Films 77 (1981) 107.

[16] S.J. Dixit, A.K. Rai, R.S. Bhattacharya, S. Guha, T. Wittberg, Thin Solid Films 398/399 (2001) 17.

[17] J. Szczyrbowski, G. Briiuer, G. Teschner, A. Zmelty, J. Non-Cryst. Solids 218 (1997) 25.

[18] G. San Vicente, A. Morales, M.T. Gutierrez, Thin Solid Films 391 (2001) 133.

[19] A.G. Spencer, M. Georgson, C.A. Bishop, E. Stenberg, R.P. Howson, Sol. Energy Mater. 18 (1988) 87.

[20] Y. Claesson, M. Georgson, A. Roos, C.-G. Ribbing, Sol. Energy Mater. 20 (1990) 455.

[21] M.A. Auger, R. Gago, M. Fernández, O. Sánchez, J.M. Albella, Surf. Coat. Technol. 157 (2002) 26.

[22] D. Poelman, P. Frederic Smet, J. Phys. D: Appl. Phys. 36 (2003) 1850.

[23] A. Climent-Font, F. Pászti, G. García, M.T. Fernández-Jiménez, F. Agulló, Nucl. Instrum. Methods Phys. Res., B 219/220 (2004) 400.

[24] E. Kotai, Nucl. Instrum. Methods Phys. Res. B 85 (1994) 588

[25] PCPDFWIN version 2.2 (c) 2001 JCPDS-ICDD. 